https://helda.helsinki.fi

\title{
Professional supervision and professional autonomy
}

\section{Karvinen-Niinikoski, Synnove}

2019

Karvinen-Niinikoski , S , Beddoe , L , Ruch , G \& Tsui , M 2019 , ' Professional supervision and professional autonomy ' , Aoteraoa New Zealand Social Work, vol. 31 , no. 3 , pp. 87-96 . https://doi.org/10.11157/anzswj-vol31iss3id650

http://hdl.handle.net/10138/310777

https://doi.org/10.11157/anzswj-vol31iss3id650

cc_by

publishedVersion

Downloaded from Helda, University of Helsinki institutional repository.

This is an electronic reprint of the original article.

This reprint may differ from the original in pagination and typographic detail.

Please cite the original version. 


\title{
Professional supervision and professional autonomy
}

\author{
Synnöve Karvinen-Niinikoski ${ }^{1}$, Liz Beddoe ${ }^{2}$, Gillian Ruch ${ }^{3}$ and Ming-sum Tsui ${ }^{4}$
}

\begin{abstract}
INTRODUCTION: Supervision is a well-established component of practice in the health and social care professions. In recent years, however, relentless changes in the nature of professional roles within these contexts have led to corresponding variations in how professional practice supervision is configured and delivered.
\end{abstract}

METHOD: This article examines how professional supervision and its future are seen by an international group of experts in social work supervision. The evolving perceptions of social work supervision's role, and the relationship to professional autonomy in the social sphere are explored with reference to the authors' earlier research.

FINDINGS: The tension between supervision as a surveillant tool of management and a practice of critical reflection is acknowledged in literature as posing a threat to one aspect of professional autonomy and agency.

IMPLICATIONS: The authors pose an alternative, theoretically grounded, approach based on the traditions of critically reflective supervision to assist the recognition and management of the balance between support and surveillance or managerial organisational dimensions. Metatheoretical understanding of professional supervision in the frame of human agency will help both practitioners and supervisors to construct sustainable and proactive social work. Instead of despairing about the loss of autonomy, the professionals may go through significant societal and professional transformations as subjects of their own expertise and professional agency.

KEYWORDS: supervision; social work; critical reflection; managerialism; professional autonomy and agency

Through professional supervision, practitioners engage in a relationship with a supervisor enabling both a place and space to refine and develop professional identity, knowledge and skills and for reflectively examining the challenges faced in everyday practice. Supervision itself has a long history and is a well-established component of the health and social care professions. In recent years, however, relentless changes in the nature of professional roles within these contexts have led to corresponding variations in how professional practice supervision is configured and delivered (Karvinen-Niinikoski, 2009). As a contested practice, the linking of supervision and managerial surveillance in social work is not new (Beddoe, 2010); this tension is also considered in Karvinen-Niinikoski's (2004) discussion on critical reflection and supervision.

These challenges are increasingly associated with the dominance of
${ }^{1}$ University of Helsinki, Finland

2 University of Auckland, New Zealand

${ }^{3}$ University of Sussex, United Kingdom

${ }^{4}$ Caritas Institute of Higher Education, Hong Kong
AOTEAROA

NEW ZEALAND SOCIAL WORK 31(3), 87-96.

CORRESPONDENCE TO: Liz Beddoe e.beddoe@auckland.ac.nz 
New Public Management (NPM) practices and their influence on the management of social work services (Beddoe et al., 2014). Manthorpe et al. (2013, p. 3) note the presence of a kind of dyadic approach in discussions of supervision in social work, where supervision is grasped either as largely introspective (a therapeutic model) or as its antithesis, an instrumental tool for surveillance and the soft exercise of power and authority. Autonomous professionals are presented as reflective professionals with demands for reflexivity in their agency and for relational expertise. In social work they report work stress associated with feelings of losing their professional autonomy and commonly experience a sense of management intrusion into clinical decision-making (Lymbery, 1998). With the advent of new models of public management, and technologies of control such as evidence-based practice and clinical governance, managerial bureaucracies are asserting greater control of the professions than ever (Coburn, 2006). In response to these changes the expansion of supervision can be understood as a likely forum for the maintenance and development of unique professional expertise.

Tensions between professional autonomy and managerial accountability are also reflected in the changing positions of professions more broadly (Tsui \& Cheung, 2004). The links between NPM and professionalism in the public service context of western post-industrial societies has been examined by Evetts (2009). Evetts was interested in clarifying to what extent a new and different type of professionalism is developing and depicts an emerging mixture of two ideal types of professions: the organisational and the occupational. The first type is manifested in a discourse of control used increasingly by managers in workplaces. The latter is based on practitioner autonomy, discretionary judgment and assessment, particularly in complex cases, and resonates with perceptions of supervision in social work settings.
Concerns about professional autonomy are widely expressed by professionals and researchers in the welfare professions. Within the field of social work this is a constant issue arguably connected to the expansion of NPM in neoliberal regimes and the reconfigurations of welfare services associated with them. For social workers in particular, anxieties about professional autonomy appear particularly salient and associated with a fear of professional freedom being constrained in the face of the controlling nature of NPM practices and attendant bureaucracy. In turn this can be experienced as an undermining of the profession's basic values. This call for professional autonomy seems relentless and imbued with a deterministic resignation. It is also suggested that processes that have become visible in sociological studies on welfare professions (for example, Evans, 2010) which acknowledge that the position of professionals is being changed within the organisational re-arrangement of welfare services are also a reality for social work professionals.

Within this climate of anxiety, the safeguarding of professional autonomy, expertise and identity (Evans \& Harris, 2004) becomes a significant agenda item for professionalisation interests and projects. In this respect, for many professions supervision has been an important medium for strengthening professional identity, identifying coping strategies for personal survival and growth, facilitating the utilisation and transfer of knowledge, as well as being a guarantee of professional quality and credibility. Negotiating new positions within this changing professional context with its new power structures and service demands is not easy but it does raise the question of how a somewhat defeatist cry for professional autonomy could evolve into a more empowering approach. One alternative, within the social work profession, is found in efforts to strengthen professional autonomy through professional supervision and, in doing so, securing both the quality of 
professional work and the wellbeing of practitioners.

In this article we examine how professional supervision and its future are seen by an international group of experts in social work supervision. The aim is to explore evolving perceptions of social work supervision's role, and to what extent these reflections relate to professional autonomy as a central feature of the developmental tensions discussed earlier. The topic has a background in the authors' shared interest in exploring supervision research on an international scale. For this purpose, a Delphi study was conducted to establish an international dialogue about the visions and prospects of social work supervision and its scholarship and research (Beddoe, Karvinen-Niinikoski, Ruch, \& Tsui, 2016). The study posed questions on topics such as what social work supervision would look like in 10 years' time and which aspects of it are most worthy of scholarly research. Drawing on data from the Delphi survey and an emerging meta-theoretical understanding of professional supervision as a vehicle for promoting critical professional agency, we will discuss some tensions found in the material in relation to professional supervision and development. These dyadic, even circular, reflections reflect how professionals position themselves in changing contexts and the extent to which they experience workplace constraints as threats to their work. Placing supervision in a frame of theoretical understanding of human agency (Emirbayer \& Mische, 1998; Eteläpelto, Vähäsantanen, Hökkä, \& Paloniemi, 2013) and thus opening a metatheoretical understanding of supervision, could help the profession undergo significant transformation while remaining subjects of their own expertise.

\section{Central concepts: autonomy, discretion, agency and supervision}

The concepts of professional autonomy and supervision are intertwined with a further two topical, and inextricably interconnected, concepts: professional agency and discretion.

\section{Professional autonomy}

Professional autonomy (Brante, 2011) is a concept emerging from the professionalisation processes within modern society and theories of professions and professional power (Abbott, 1988). The field of the professions is, according to Abbott, a place of continuous struggle for professional jurisdiction: the owning of the expertise in a particular realm of service. Other theorists of the professions emphasise the safeguarding of professional power with professional autonomy as one central feature (Freidson, 2001). Autonomy is a core concept for classical professionalisation theories (Abbott, 1988) and might be the most salient issue for any profession. Following Abbott's theory, owning this autonomous professional status can be seen as competing for professional and societal power and for legitimacy and jurisdiction of field expertise. The salience of autonomy could also be read as professional freedom that is particularly susceptible to collapse with the expansion of controlling NPM policies and their attendant bureaucratic rules (Evans, 2013; Evetts, 2009).

In the face of rapid structural, societal and political change and shifting epistemological understandings and knowledge policies, professional monopolies have been challenged (Knorr-Cetina, 2007). Consequently, for some decades, the traditional pillars of professional power systems - expertise (knowledge and know-how), institutions (socio-legal structures for exercising expertise) and professional status (power over expertise)-have been progressively undermined and weakened and professional autonomy is experienced as being under threat (Chandler, Berg, Ellison, \& Barry, 2017; Evetts, 2009)in many professions, including social work. These threatening processes are identified in neoliberal systems of governance and NPM practices that build on new kinds of control, direction and power systems involving process models and standardisation, invariably based on computerised systems and accountability regimes. Here health and social care professionals face new challenges and risk a 
diminution of their autonomy. What remains, conceptually, from this loss is today often discussed as professional discretion (Evans, 2010).

\section{Professional discretion}

Professional discretion (Evans, 2010, 2013) refers to the relationship between professional agency and organisational rules and to the tension between policy and day-to-day professional practice as a key question in policy and practice. This, in turn, causes problems for professional ethics and, of course, for professional autonomy (KarvinenNiinikoski, 2009). The concept stems from Lipsky's classical work on 'Street level bureaucracy' (1980) which states that "policy implementation in the end comes down to the people who actually implement it" an issue that immediately resonates with understandings of supervision, professional autonomy and agency. Professional discretion is also a concept that challenges the professional cry for the lost autonomy of the professional subject. It resists the configuration of professionals as simply the passive recipients of instructions and structural restrictions and seeks to position them as individuals who possess transformative and responsible professional agency.

\section{Professional agency}

Agency, in the context of concerns regarding professional autonomy, can be understood as a mediating concept situated between professional discretion and freedom and the contextual and organisational control contributing to a loss of autonomy and even threatening the core values of professional social work. Agency is also a core concept when discussing critical reflection, professional identity and the subjective position of professionals and, in this sense, it stands as a central concept for theories of supervision. Professional agency is strongly associated with critical reflection and thus lies at the heart of discourses on supervision, adult and professional learning (Eteläpelto et al., 2013; Karvinen-Niinikoski, 2009).
According to Eteläpelto et al. (2013), since the 1970s, or alternatively, from 2000 and Mezirow's and Freire's critical pedagogy, Giddens' structuration theory and Archer's critical realism, there has been a growing interest in agency in various scientific fields. The combination of agency and personal identity has continued through feminist poststructuralism into socio-cultural approaches, such as the theory of expansive learning and understandings of the subject positioning of individual agency. By analysing these conceptual developments and drawing from their empirical research Eteläpelto et al. (2013, p. 62) sum up a subject-centred, sociocultural approach to professional agency. They conclude that professional agency means that vocational subjects and / or communities are entitled to make choices and use their discretion in ways that impact on their work and / or professional identity. Through their personal and professional capacities individuals hold certain agentic resources and engage discursively with all these factors maintaining temporal connections from the past through to the future.

Rediscovered in discourses on coping with the pressures of diminishing autonomy, for example in social work under the NPM regimes (Kam, 2014), professional agency can be considered as a core concept in recapturing the concept of professional autonomy and connects closely with the concept professional discretion (Eteläpelto et al, 2013; Evans, 2010). Professional contexts' agency can arguably be seen as an achievement/aim, in which both discretion and the dynamic challenges of working life are met in processes of regeneration and transformation. Control and understanding of professional agency, however, is complicated and raises tensions between practitioners and management (Beddoe, 2010). This has been reflected in the concerns of Nordic social work professionals and academics experiencing continuous restriction of jurisdiction and professional autonomy (Røysum, 2010). In Evetts' (2009) analysis of the managerial confusion and tension governing the two emerging ideal 
types of professionalism (organisational and occupational), it could be suggested that the primary concern focuses on agency (that is, on being an active societal actor) and its constraints on professionals. Thus the link between autonomy and agency becomes central for supervision which, in NPM regimes, is also regarded as a sophisticated tool for governance and control.

Agency and discretion are complex concepts, pivotal to the efforts of supervision to help social workers understand their own agency as reflexive professionals in challenging working conditions in a complex society. Agency and its link to the expression of professional identities can also be seen as a central element in theoretical understandings of supervision in reaching a meta-theoretical understanding of the functional mechanisms of supervision.

\section{Professional supervision}

As an essential part of professional and occupational practice, supervision is a key factor in the promotion of practice excellence, productivity and practitioner retention (Koivu, 2013). In emotionally demanding human professions like social work, supervision can provide a necessary containment of emotional relationships and pressures and thus may also perform occupational health functions (Adamson, 2012). In social work, a contested profession from the outset (Houston, 2002), supervision has a long tradition as a process employed to safeguard professional autonomy and expertise and, further, to resist threats to its professional jurisdiction (Tsui, 2005). The centrality of professional and personal growth to the classical aim of supervision is founded on the theoretically grounded ideas of continuous professional development, as well as on more or less hidden ideas of safeguarding professional autonomy (Tsui, 2005). Concerns to protect professional autonomy are manifest in the Nordic context by a strong emphasis on ensuring that the supervisor is external to the employing welfare service organisation (KarvinenNiinikoski \& Salonen, 2005).
Traditionally supervision has focused on promoting high quality professional services by supporting the learning, management and development of professional practice amongst individuals and groups of practitioners in human services professions. An expansion of professional or "clinical supervision" (Koivu, 2013) has stemmed from recent research on work-related wellbeing and transformative leadership that emphasise the importance of employee engagement in a participative ethos for fostering innovative potential and promoting productivity (Yliruka \& KarvinenNiinikoski, 2013).

Human services work is considered to be emotionally burdening and cognitively challenging because professional values are an essential part of professional expertise providing legitimacy and justification for the professional field in question. In daily practice these values and interests are blurred and require, for clarity, reflective practice. Supervision has traditionally provided a mechanism to promote professional reflection and enhance the quality of services. In recent decades the "preoccupation with ... systems of accountability" can be attributed in large part to the "critique of professional practice" ... and a "crisis of trust in professionals" (Davys \& Beddoe, 2010, pp. 13-14). This crisis, according to Evetts (2009, pp. 258 262 ) is a major factor behind changes to professionalising processes and the associated tensions. Within this climate of anxiety about trustworthiness, the safeguarding of professional autonomy, expertise and identity (Evans \& Harris, 2004) has become significant for professional projects.

\section{Circular reflections and concerns about professional autonomy and supervision}

Our interest in discussing the relationship between professional autonomy and supervision was roused by often reported concerns about threats to professional autonomy and worsening working conditions in social work, expressed both in research and professional debates 
in social work and supervision. The concerns found in the literature (Beddoe et al., 2016) informed the design of the Delphi survey which sought to obtain internationally comparative knowledge about contemporary understandings of social work supervision and perceptions of research gaps in this domain. Our aim in the first phase of the Delphi study on supervision (Beddoe et al., 2016) was to learn about expert opinions and visions about the present state of social work supervision and to gain ideas about the focus of future supervision research.

This study, was designed as a multi-phase project involving the delivery of two open-ended questionnaires to experts and important stakeholders, such as those with academic expertise in supervision and those whom we might define as "expert users", for example, individuals involved in supervision as expert practitioners, practice teachers, trainers and those who might be influential in developing and implementing supervision policies within social service organisations. In the replies to this survey reflections were offered by 53 participants from five continents and 15 countries providing a generous data set, though somewhat skewed towards Anglophone countries. Delphi sampling is not intended to be representative but is a means for recruiting knowledgeable, committed participants into a process that pools ideas and creates potential for sophisticated reflections. The analysis of the challenges facing the practice of social work supervision was conducted via thematic coding. Organisational and political factors loomed large as significant influences on how supervision was (or was not) promoted and supported. The impact of service budget cuts under recessionary government policies were also frequently mentioned, along with the impact of a pervasive risk-averse climate (Beddoe et al., 2016).

A somewhat surprising feature of the Delphi study results was how strongly and critically respondents expressed their concerns about the loss of, and threats to, professional discretion and autonomy in social work supervision. These concerns stretched beyond simply threats to professional identity and encompassed fear of the demise of professional supervision as a forum for critical reflection and a site for discussing social work practice related ethical matters. Reflections illuminating these concerns emerged in response to future focused questions on social work supervision and its significance in practice governance. The answers to these reflected themes around autonomy and proved to be quite circular: drawing both on expressions of the role of supervision in promoting professional strength and fear of supervision becoming a forum for losing power.

One participant captures this circularity: "I fear it's a circular debate and we might be in the same space again and again." Behind this circularity sits tension and uncertainty about how supervision will be used: for "management/ competence or reflective learning" or to enhance a "strong but diverse profession mandated to be registered and well educated, critical and expansive thinkers and experimenters.... A group that is bold and able ... creative, experimental ... and radiating hope and innovation...", instead of leaving the profession to stay as "a divided non-professional group who has subsumed or gone beyond social control and re-apportioning dwindling resources". These alternatives reflect social work preoccupations with social justice and the dispositions needed to meet the challenges social workers "face in societies in a local, regional and global sense of the work". These are, in many senses, the core values attached to professional autonomy in social work, and perceived as under threat.

Supervision is also described in optimistic terms, one participant hoping that "social work supervision would be recognised as an important social work practice domain" benefiting both "clients and supervisees". 
It is also advocated that "social work supervision is conducted more rigorously, making use of what we know works for staff, service users and organisations from the evidence base". There is also a hope that there will be "the momentum towards reflective practice" that would mean "that reflective supervision is highly valued and prioritized within the provision of social work services". Most optimistically this was expressed as: "the profile of social work supervision is developing. I would like to see it develop further. Supervision and reflection are essential to the ongoing existence of social work practice in this sense. It is the space away from pressures of practice and mechanistic culture that has developed in the last 30 years". Most important, however, is being supported and valued for coping with the demanding and difficult work: "[s]ocial workers need support to resist and creatively challenge the neoliberal intensification of blaming the person, family or community for things the economic systems produce" and that "[s]upervision must encompass the ability to look beyond the individual and connect the dots to systemic cause and effect ... basically social work supervision mirrors and supports social work practice".

When asked about the future, many participants seemed rather resigned: "if nothing is done intentionally, supervision could become nothing more than a tool for administrative surveillance". It is seen to be "pretty well the same-it is not the political climate for much change"; or "more pressed for time; poorer quality" with no improvement; or "not prioritized-worse"; or "sadly, I do not think there will be a significant shift". The worsening visions are placed "in the context of social welfare organisations due to increasing concern about management, quantitative output and manpower cut[s]". Similar concerns could be discerned 'between the lines' when asked about the most important and urgent questions for research in supervision. There is an interest in refocusing "the practice and discipline value of supervision, understanding that balancing administrative needs will continue to be an ongoing challenge ... [for example] How do supervisors use their power so that social workers' knowledge and skills are valued and developed?" Parallel to seeing supervision as support to professional autonomy there is the concern about the risk to professional agency and autonomy of having a supervisor as an outsider to one's own profession (Beddoe \& Howard, 2012; Hojer \& Bradley, 2009). For example, one participant commented: "[I am] not clear how increased regulation will address the need for competent supervision, especially when many other disciplines are represented in the ranks of supervisors."

The reason for this resignation, hesitation and sadness seems to reflect a loss of professional self-determination and autonomy. For one informant this involved supervision aligning itself with neoliberalistic trends and narrower definitions of social work and supervision: "I fear that social work's push for professionalism and accreditation in supervision and practice ... is unintentionally dove tailing with, and supporting neo-liberal, managerial, consumerist influences that continue to narrow, shape, re-define what seem reasonable of possible within social work and social work supervision. ... I fear that as social workers we are contributing to devaluing the core of our work". A particularly gloomy vision was that, "at worst a divided non-professionalised group who have been subsumed or persuaded by politics of individual blame shame and greed and are unable to go beyond social control and re-apportioning dwindling resources on a 'deserving' qualifying criteria that keeps people in boxes and places of non-participation and disenfranchisement".

One is left pondering how circular the argumentation is, repeating the risks of losing autonomy and hoping for professional supervision to have the strength to build support for sound social work practice. 


\section{Discussion: how to cross the circular cycles of professional concerns}

The narrative of perceived challenges to professional autonomy alongside hopes for improving the positioning of the profession via the future development of supervision which emerges from this study suggests that the concept of supervision is understood and indeed utilised in many different ways in various contexts (Beddoe, 2015). Alluding to this issue of context and location in approaches to supervision, a research participant commented that, "supervision in social work needs to engage with local and global knowledge to assist social workers wherever they are to maintain their focus on meeting the practical and emotional needs of the individuals, families and communities they serve, in an economic climate where this is increasingly difficult".

The cycle of threats and hopes regarding professional autonomy and values based social work practice suggest ambiguous responses to changing realities. This is understandable given the trends, described by Evetts (2009), towards the organisational and occupational professions having diminishing powers when considering the more positive future visions it is possible to identify a determination to become stronger, regardless of pressures and constraints. This leaves us with a question as to whether the missing and mediating cycle-breaking concept might actually be the professional agency so central to professional identity and professional emancipation.

As posed by Eteläpelto et al. (2013), professional agency is a powerful concept dealing with the professional's identity and capability for making choices and using discretional opportunities in ways that impact on their work and/or professional identity. This also means disrupting the circular structures and crossing the boundaries of professional discourses, be they singularly profession centred or multi-professionally relational as Edwards
(2010) has it. Agency is a concept based on careful ontological analyses of the issues and tensions between individual action and structural constraints (Emirbayer \& Mische, 1998; Eteläpelto et al., 2013); the dynamics inherent in the research can be construed as practitioners experiencing a loss of professional autonomy.

An understanding of professional agency is needed especially for creatively developing one's own work and working contexts, for learning at work and for negotiating professional identity (Eteläpelto et al., 2013). It is needed in order to see the options for taking professional responsibility and action. The theoretical understanding of agency might help solve the helplessness syndrome of social work expressed in the circular argumentation above. It is very much what one tries to promote when tackling the circular concerns of losing professional autonomy. Understanding one's own agency and its relation to both professional discretion and autonomy might help emancipating social work to cope with the changing professional structures in changing societies (Kam, 2014).

\section{Conclusion}

These reflections on supervision and its future raise questions about the logic of a persistent circular professional discourse that is creating and perpetuating resigned attitudes around social work. There remains a strong belief, however, in supervision as an emancipatory support for professional self-respect and identity. It is the potential loss of professional autonomy that may be seen as a major tension. This is also seen in the fear of losing supervision as a reflective professional sphere where a genuine social work professional and ethical ethos can be fostered. These tensions and fears appear similar to those factors lying behind the "tension model of changing professionalization" presented by Evetts (2009). The same kinds of discussions have been identified also in the late concerns of losing 'the social' from social 
work (Røysum, 2010) and even the loss of the social itself (Kam, 2014). The tension model also provides a concept with which to analyse and understand human actors' positions and discretional opportunities in professional practice, in between individual and structural factors and constraints, the factors that are considered as opposite poles in the reflections on the future of social work and supervision.

There is also a strong alternative, and theoretically grounded, approach based on the traditions of "critically reflective supervision" helping to recognise and manage the fine balance between support and surveillance or managerial organisational dimensions. Metatheoretical understanding of professional supervision in the frame of human agency will help both practitioners and supervisors to construct sustainable and proactive social work. Instead of despairing about the loss of autonomy, the professionals may go through significant societal and professional transformations as subjects of their own expertise and professional agency.

\section{Note:}

The body of this article was originally published in Björn Blom, Lars Evertsson and Marek Perlinski (2017) (Eds.), Social and caring professions in European welfare states. Re-published with permission of Policy Press (an imprint of Bristol University Press, UK).

Karvinen-Niinikoski, S., Beddoe, L., Ruch, G., \& Tsui, M. s. (2017). Professional supervision and professional autonomy. In B. Blom, L. Evertsson, \& M. Perlinski (Eds.), Social and caring professions in European welfare states (pp. 53-66). Bristol, UK: Policy Press.

\section{References}

Abbott, A. (1988). The system of professions. An essay on the division of the expert labour. Chicago, IL: UCP.

Adamson, C. (2012). Supervision is not politically innocent. Australian Social Work, 65(2), 185-196. doi:10.1080/031 2407x.2011.618544

Beddoe, L. (2010). External supervision in social work: Power, space, risk, and the search for safety. Australian Social Work, 65(2), 197-213. doi:10.1080/0312407x.2011.591187

Beddoe, L. (2015). Supervision and developing the profession: One supervision or many? China Journal of Social Work, 8(2), 150-163. doi:10.1080/17525098.201 5.1039173
Beddoe, L., \& Howard, F. (2012). Interprofessional supervision in social work and psychology: mandates and (inter) professional relationships. The Clinical Supervisor, 31(2), 178-202. doi:10.1080/07325223.201 3.730471

Beddoe, L., Karvinen-Niinikoski, S., Ruch, G., \& Tsui, M-S. (2014). Supervision in social work: Project Blog. Retrieved from http://socialworksupervisionagenda. wordpress.com/

Beddoe, L., Karvinen-Niinikoski, S., Ruch, G., \& Tsui, M.-s. (2016). Towards an international consensus on a research agenda for social work supervision: Report on the first survey of a Delphi study. The British Journal of Social Work, 46(6), 1568-1586. doi:10.1093/bjsw/bcv110

Blom, B., Evertsson, L., \& Perlinski , M. (2017). (Eds.), Social and caring professions in European welfare states. Bristol, UK: Policy Press.

Brante, T. (2011). Professions as science-based occupations. Professions \& Professionalization, 1(1), 4-20.

Chandler, J., Ellison, M., Berg, E., \& Barry, J. (2017). Reconfiguring professional autonomy? The case of social work in the UK. In B. Blom, L. Evertsson, \& M. Perlinski (Eds.), Social and caring professions in European welfare states (pp. 69-82). Bristol, UK: Policy Press.

Coburn, D. (2006). Medical dominance then and now: A critical reflection. Health Sociology Review, 15(5), 432-443.

Davys, A., \& Beddoe, L. (2010). Best practice in professional supervision. A guide for the helping professions. London, UK: Jessica Kingsley Publishers.

Edwards, A. (2010). Being an expert professional practitioner. The relational turn in expertise. London, UK: Springer.

Emirbayer, M., \& Mische, A. (1998). What is agency? American Journal of Sociology, 103(4), 962-1023.

Eteläpelto, A., Vähäsantanen, K., Hökkä, P., \& Paloniemi, S. (2013). What is professional agency? Conceptualising professional agency at work. Educational Research Review, 10, 45-65.

Evans, T. (2010). Professional discretion in welfare services: Beyond street-level bureaucracy. Aldershot UK: Ashgate.

Evans, T. (2013). Organisational rules and discretion in adult social work. British Journal of Social Work, 43, 739-758.

Evans, T., \& Harris, J. (2004). Street-level bureaucracy, social work and the (exaggerated) death of discretion. British Journal of Social Work, 34(6), 871-895.

Evetts, J. (2009). New professionalism and New Public Management: Changes, continuities and consequences. Comparative Sociology, 8, 247-266.

Freidson, E. (2001). Professionalism. The third logic. Cambridge, UK: Wiley/Polity.

Hojer, S., \& Bradley, G. (2009). Supervision reviewed: Reflections on two different social work models in England and Sweden. European Journal of Social Work, 12(1), 71-85.

Houston, S. (2002). Reflecting on habitus, field and capital: Towards a culturally sensitive social work. Journal of Social Work, 2(2), 149-167.

Kam, P. K. (2014). Back to the "social" of social work: Reviving the social work profession's contribution to the promotion of social justice. International Social Work, 57(6), 723-740. doi:10.1177/0020872812447118 
Karvinen-Niinikoski, S. (2004). Social work supervision: Contributing to innovative knowledge production and open expertise. In N. Gould \& M. Baldwin (Eds.), Social work, critical reflection and the learning organisation (pp. 23-40). Aldershot UK: Ashgate.

Karvinen-Niinikoski, S. (2009). Promises and pressures of critical reflection for social work coping in change. European Journal of Social Work, 12(3), 333-348.

Karvinen-Niinikoski, S., \& Salonen, J. (2005). Spänningar inom handledningsdiskussionen [Tensions in discussing supervision]. Nordisk sosialt arbeid 3/2005.

Knorr-Cetina, K. (2007). Culture in global knowledge societies: Knowledge cultures and epistemic cultures. Interdisciplinary Science Reviews, 32(4), 361-375.

Koivu, A. (2013). Clinical supervision and well-being at work: A four-year follow-up study on female hospital nurses. Publications of the University of Eastern Finland. Dissertations in Health Sciences. Retrieved from http://epublications.uef.fi/

Lipsky, M. (1980). Street-level bureaucracy: Dilemmas of the individuals in public service. New York, NY: Russell Sage Foundation.

Lymbery, M. (1998). Care management and professional autonomy: The impact of community care legislation on social work with older people. British Journal of Social Work, 28(6), 863-878.

Manthorpe, J., Moriarty, J., Hussein, S., Stevens, M., \& Sharpe, E. (2013). Content and purpose of supervision in social work practice in England: Views of newly qualified social workers, managers and directors. British Journal of Social Work, 45(1), 52-68. doi:10.1093/bjsw/ bct102

Røysum, A. (2010). Nav-reformen: Sosialarbeidernes profesjon utfordres [The Na reform: A challenge to professional social work]. Fontene Forskning, 2010/1, 41-52.

Tsui, M. S. (2005). Social work supervision: Contexts and concepts. Thousand Oaks, CA: Sage Publications.

Tsui, M. S., \& Cheung F. C. H. (2004). Gone with the wind: The impacts of managerialism on human services. British Journal of Social Work, 34(3), 437-442.

Yliruka, L., \& Karvinen-Niinikoski, S. (2013). How can we enhance productivity in social work? Dynamically reflective structures, dialogic leadership and development of transformative expertise. Journal of Social Work Practice, 27(2), 191-206. 